\title{
Valores de referência e influência da idade no eritrograma de fêmeas bovinas da raça Aquitânica
}

[Reference values and age effect on the erythrogram of bovine females of the Aquitanian breed]

\author{
R.F. Dias Junior ${ }^{1}$, A.P.F.R.L. Bracarense ${ }^{1}$, W.S. Marçal $^{1}$, M.A. Rocha ${ }^{1}$, R.C.F. Dias ${ }^{2}$ \\ ${ }^{1}$ Centro de Ciências Agrárias - UEL \\ Caixa Postal 6001 \\ 86051-990- Londrina, PR \\ ${ }^{2}$ Aluna de graduação - UEL - Londrina, PR
}

\begin{abstract}
RESUMO
Determinaram-se os valores de referência e estudou-se a influência da idade sobre o eritrograma em fêmeas bovinas da raça Aquitânica. Amostras de sangue de 80 fêmeas bovinas, acima de 12 meses de idade, e não reagentes ao antígeno do vírus da leucose dos bovinos, foram colhidas utilizando-se EDTA como anticoagulante para realização das seguintes provas: contagem global das hemácias, determinação do volume globular, concentração de hemoglobina, cálculo dos índices hematimétricos absolutos volume corpuscular médio (VCM), hemoglobina corpuscular média (HCM) e concentração de hemoglobina corpuscular média $(\mathrm{CHCM})$. A idade exerceu influência significativa $(\mathrm{P} \leq 0,05)$ sobre a maioria dos parâmetros hematológicos estudados, com diminuição da quantidade de hemácias e aumento do volume globular, quantidade de hemoglobina, VCM e HCM. Os valores foram: hemácias $6,68 \pm 0,58 \times 10^{6} / \mathrm{mm}^{3}$, volume globular $41,2 \pm 4,5 \%$, hemoglobina $12,8 \pm 1,31 \mathrm{~g} / \mathrm{dl}$, VCM $61,83 \pm 6,54 \mathrm{fl}$, HCM $19,28 \pm 2,25 \mathrm{pg}$, CHCM 31,4 $\pm 2,3 \%$.
\end{abstract}

Palavras-chave: bovino, Aquitânica, hematologia, valor de referência, idade

\begin{abstract}
The reference values and the influence of the age factor on the erytrogram in bovine females of the Aquitanian breed were evaluated. Blood samples of 80 healthy females, all tested negative for bovine leucose virus, were utilized for the analysis. Erythrocyte counts, determination of the packed cell volume, concentration of hemoglobin, calculation of hematimetric absolute rates of mean corpuscular volume $(\mathrm{MCV})$, mean corpuscular hemoglobin $(\mathrm{MCH})$ and mean corpuscular hemoglobin concentration (MCHC) were evaluated. Significant influence $(P \leq 0.05)$ of age was observed for most of the hematological characteristics, with decreased of the number of erythrocytes and increase of packed cell volume, quantity of hemoglobin, MCV, MCH. The reference values were: erythrocytes counting $6.68 \pm 0.58 \times 10^{6} / \mathrm{mm}^{3}$, packed cell volume $41.2 \pm 4.5 \%$, hemoglobin $12.8 \pm 1.31 \mathrm{~g} / \mathrm{dl}$, VCM $61.83 \pm 6.54 \mathrm{fl}$, HCM 19.28 $22.25 \mathrm{pg}$, CHCM $31.4 \pm 2.3 \%$.
\end{abstract}

Keywords: bovine, Aquitanian, hematology, reference value, age

Recebido em 1 de outubro de 2004

Aceito em 23 de agosto de 2005

E-mail: rfdias@uel.br 


\section{INTRODUÇ̃̃O}

Nas últimas décadas, o interesse pelo desenvolvimento de pesquisas no campo da hematologia veterinária tem-se acentuado de maneira considerável, principalmente devido ao aperfeiçoamento das técnicas empregadas e, também, à utilização de respaldo laboratorial, na busca de soluções relativas aos problemas clínicos pertinentes às diferentes espécies animais.

Rotineiramente, um dos exames hematológicos mais utilizados é o eritrograma, definido por Kracke (1943) como um conjunto de parâmetros hematológicos, mais especificamente hematimetria, a contagem do número de hemácias $/ \mathrm{mm}^{3}$, concentração de hemoglobina em gramas/dl, volume globular (relação entre a parte líquida e sólida vermelha do sangue), cujos valores obtidos dão origem aos índices corpusculares absolutos, volume corpuscular médio (VCM), hemoglobina corpuscular média (HCM), e concentração de hemoglobina corpuscular média (CHCM).

Para a correta interpretação do eritrograma, vários pesquisadores têm procurado estabelecer valores de referência para os animais domésticos, sendo quase unânime a opinião de que eles devem ser regionais e de cada laboratório, pois são influenciados pela espécie animal, raça, sexo, idade, temperatura ambiente, altitude, nutrição, excitação do animal, gestação, puerpério, lactação e balanço hídrico (Lorenz et al., 1978; Lumsden, 1980; Jain, 1978). Assim, os valores obtidos para os bovinos criados em uma região não podem ser considerados, sem uma adequada avaliação, como padrão de referência para outra, isto é, os resultados são regionais. (Alencar Filho, 1970).

A raça Aquitânica, desenvolvida no Brasil em 1973, é o resultado do cruzamento das raças Blonde D'Aquitaine e Caracu, especificamente 5/8 Blonde D'Aquitaine e 3/8 Caracu, unindo as vantagens da adequação ao clima tropical brasileiro, características do Caracu, com o bom rendimento de carcaça, típica do gado europeu, resultando em animais com excepcional cobertura muscular, terminação precoce, rusticidade, pêlos curtos, alta fertilidade, precocidade sexual e excelente conversão alimentar. Sua boa adaptação, fertilidade e alto rendimento de carne têm sido reconhecidos em todo o país (Turra, 2004).

Este trabalho teve o objetivo de estabelecer valores de referência do eritrograma em fêmeas bovinas adultas da raça Aquitânica, clinicamente sadias, não reagentes ao antígeno do vírus da leucose bovina, criadas na região Norte do Paraná, bem como o de estudar a influência da idade sobre as características do eritrograma.

\section{MATERIAL E MÉTODOS}

Para estabelecer os valores de referência do eritrograma, em diferentes faixas etárias, foram utilizadas fêmeas bovinas da raça Aquitânica não gestantes e não lactantes acima de 12 meses de idade. Os animais foram submetidos individualmente ao exame clínico, conforme métodos e padrões recomendados por Dirksen (1993), e aos testes sorológicos para brucelose, leptospirose, tuberculose, IBR, BVD e leucose.

Os animais, mantidos em propriedades com manejo semelhante, criados em regime semiintensivo, em pastagem de braquiária (Brachiaria decumbens), foram alimentados com silagem de milho, torta de algodão e resíduo de soja amoniada fornecidos na quantidade de três a quatro quilos por dia. Foram distribuídos em quatro grupos com 20 animais cada, conforme a faixa etária: 12 a 24 meses; 24 a 48 meses; 48 a 72 meses e acima de 72 meses.

Amostras de sangue obtidas nos meses de setembro e outubro, no período da manhã, época de temperatura amena na região Norte do Paraná $\left(18,8^{\circ} \mathrm{C}\right.$ a $\left.31,4^{\circ} \mathrm{C}\right)$ e umidade relativa do ar de $68 \%$ a 78,2\% (Iapar..., 2001), foram coletadas por venopunção da jugular, acondicionadas em tubos de ensaio individuais contendo EDTA a $10 \%$, e mantidas refrigeradas até a realização dos exames de laboratório, nunca excedendo seis horas após a coleta. Foram determinados os valores de características do eritrograma (contagem global das hemácias, determinação do volume globular e dosagem de hemoglobina) e calculados os índices hematimétricos absolutos (VCM, HCM e CHCM), conforme metodologia descrita por Schalm et al. (1975). Para a determinação da quantidade de hemácias, concentração de hemoglobina, volume globular, VCM, HCM, CHCM, foi utilizado o contador 
hematológico de células $\mathrm{MS}^{1}$ por meio do sistema de contagem elétrica (impedância). As análises foram em duplicata (Schalm et al., 1975), para confirmação do volume globular calculado pelo contador MS4.

Os dados obtidos foram analisados pelo modelo matemático abaixo, utilizando-se o programa de computador SAEG (Sistema..., 1993). O modelo matemático usado foi:

$\mathrm{Y}_{\mathrm{IJ} \mathrm{k}}=\mu+\mathrm{I}_{\mathrm{i}}+\mathrm{E}_{\mathrm{ijk}}$, em que:

$\mathrm{Y}_{\mathrm{ijk}}=$ variáveis avaliadas nos animais $(\mathrm{k})$, com idade $\left({ }_{i}\right)$ pertencente a propriedade $\left({ }_{j}\right)$;

$\mu=$ média geral;

$\mathrm{I}=$ efeito da idade $\left({ }_{\mathrm{i}}\right)$;

$\mathrm{E}_{\mathrm{ijk}}=$ erro experimental.

\section{RESULTADOS E DISCUSSÃO}

Os valores de referência do eritrograma, estabelecidos em 80 fêmeas bovinas adultas da raça Aquitânica, são apresentados na Tab 1. Devido à ausência de estudos sobre o eritrograma na raça Aquitânica, eles foram comparados com dados da literatura para bovinos adultos de outras raças (Marçal, et al., 1995; Távora, 1997; Birgel Junior et al., 2001; Costa, 1994; Fagliari et al., 1998; Ayres, 2001), observando-se resultados semelhantes.

As médias, os desvios-padrão e as amplitudes de variação para o número de hemácias, volume globular e hemoglobina, de acordo com a idade, são apresentados na Tab. 2. O número de hemácias oscilou entre 6,49 e $6,95 \times 10^{6} / \mathrm{mm}^{3}$, os menores valores ocorreram em animais acima de 48 meses, fato relatado em diversas raças bovinas (Mammericks et al., 1978; Marçal, 1989; Ayres, 1994; Távora, 1997). Fagliari et al. (1998) não observaram influência da idade sobre o número de hemácias nas raças Nelore e Holandesa.

Tabela 1. Valores de referência, desvio-padrão e amplitude de variação de constituintes hematológicos de fêmeas bovinas com idade acima de 12 meses da raça Aquitânica, criadas na região Norte do Paraná

\begin{tabular}{lcc}
\hline Eritrograma & Média \pm desvio-padrão & Amplitude de variação \\
\hline Hemácias $\left(\mathrm{x} 10^{6} / \mathrm{mm}^{3}\right)$ & $6,68 \pm 0,58$ & $5,04-7,71$ \\
Volume globular $(\%)$ & $41,20 \pm 4,5$ & $31,00-51,8$ \\
Hemoglobina $(\mathrm{g} / \mathrm{dl})$ & $12,80 \pm 1,31$ & $9,30-16,3$ \\
VCM (fl) & $61,83 \pm 6,54$ & $45,10-73,5$ \\
HCM (pg) & $19,28 \pm 2,25$ & $14,10-23,7$ \\
CHCM (\%) & $31,41 \pm 2,3$ & $25,50-35,6$ \\
\hline
\end{tabular}

$\mathrm{VCM}=$ volume corpuscular médio; $\mathrm{HCM}=$ hemoglobina corpuscular média; $\mathrm{CHCM}=$ concentração de hemoglobina corpuscular média.

Tabela 2. Média, desvio-padrão $(\overline{\mathrm{x}} \pm \mathrm{s})$ e amplitude de variação do número de hemácias, volume globular e teor de hemoglobina, segundo a idade, em fêmeas bovinas da raça Aquitânica criadas na região Norte do Paraná

\begin{tabular}{lcccc}
\hline Idade(meses) & Número de animais & Hemácia $\times 10^{6} / \mathrm{mm}^{3}$ & Volume globular(\%) & Hemoglobina $(\mathrm{g} / \mathrm{dl})$ \\
\hline 12 a 24 & 20 & $6,69 \pm 0,69 \mathrm{ab}$ & $39,8 \pm 4,9 \mathrm{~b}$ & $12,40 \pm 1,57 \mathrm{~b}$ \\
& & $(5,04-7,77)$ & $(31-50,6)$ & $(9,6-14,7)$ \\
$24 \mathrm{a} 48$ & 20 & $6,95 \pm 0,36 \mathrm{a}$ & $40,7 \pm 3,3 \mathrm{~b}$ & $12,70 \pm 0,86 \mathrm{~b}$ \\
& & $(6,29-7,51)$ & $(36,2-46,0)$ & $(11,6-14,5)$ \\
48 a 72 & 20 & $6,49 \pm 0,63 \mathrm{~b}$ & $40,3 \pm 4,0 \mathrm{~b}$ & $12,80 \pm 0,63 \mathrm{ab}$ \\
& & $(5,38-7,63)$ & $(35,1-51,6)$ & $(11,6-14,1)$ \\
72 & 20 & $6,59 \pm 0,53 \mathrm{ab}$ & $44,1 \pm 4,5 \mathrm{a}$ & $13,66 \pm 0,53 \mathrm{a}$ \\
& & $(5,34-7,51)$ & $(34,1-51,8)$ & $(10,6-16,3)$ \\
\hline
\end{tabular}

Médias seguidas por letras distintas na coluna diferem entre si pelo teste Tukey $(\mathrm{P}<0,05)$. Valores entre parênteses indicam amplitude de variação

\footnotetext{
${ }^{1}$ Melet Schloesing Laboratoires - França
} 
Os valores do volume globular oscilaram entre $39,8 \%$ e $44,1 \%$. O maior valor foi observado em animais com idade superior a 72 meses, significativamente diferente de todas as outras faixas etárias $(\mathrm{P}<0,05)$. Os resultados assemelham-se aos encontrados por Marçal (1989), na raça Holandesa, Gonçalves et al. (2001), na raça Guzerá.

O teor de hemoglobina oscilou entre 12,40 e $13,66 \mathrm{~g} / \mathrm{dl}$, mas a variação, segundo a idade, só foi significativa entre animais mais jovens e animais com mais de 72 meses de idade. A influência do fator etário no aumento da taxa de hemoglobina também foi relatada por Wingfield e Tumbleson (1973) e Ayres (1994). Alguns autores não observaram diferenças atribuídas à idade, em várias raças de bovinos (Marçal, 1989; Fagliari et al., 1998; Birgel Junior et al, 2001).

As médias, os desvios-padrão e as amplitudes de variação para o VCM, HCM e CHCM, de acordo com a idade, são apresentados na Tab 3.

Tabela 3. Média, desvio-padrão $(\mathrm{x} \pm \mathrm{s})$ e amplitude de variação do volume corpuscular médio (VCM), hemoglobina corpuscular média (HCM) e concentração de hemoglobina corpuscular média (CHCM), segundo a idade, em fêmeas bovinas da raça Aquitânica criadas na região Norte do Paraná

\begin{tabular}{lcccc}
\hline Idade (meses) & Número de animais & VCM (fl) & HCM (pg) & CHCM (\%) \\
\hline 12 a 24 & 20 & $59,38 \pm 8,98 \mathrm{~b}$ & $18,73 \pm 2,66 \mathrm{bc}$ & $31,6 \pm 3,3 \mathrm{a}$ \\
& & $(45,1-75,1)$ & $(14,1-22,9)$ & $(27-35,6)$ \\
24 a 48 & 20 & $58,70 \pm 2,97 \mathrm{~b}$ & $18,01 \pm 2,09 \mathrm{c}$ & $31,3 \pm 2,7 \mathrm{a}$ \\
& & $(55,6-65,1)$ & $(17,5-20,3)$ & $(25,5-33,7)$ \\
48 a 72 & 20 & $62,29 \pm 5,04 \mathrm{~b}$ & $19,76 \pm 1,85 \mathrm{ab}$ & $31,8 \pm 1,4 \mathrm{a}$ \\
& & $(55,8-73)$ & $(17,4-23,5)$ & $(28,4-33,3)$ \\
& & $66,97 \pm 4,25 \mathrm{a}$ & $20,63 \pm 1,42 \mathrm{a}$ & $30,9 \pm 0,83 \mathrm{a}$ \\
& 20 & $(56,7-73,5)$ & $(17,6-23,7)$ & $(29,4-32,4)$ \\
\hline
\end{tabular}

Médias seguidas por letras distintas na coluna diferem entre si pelo Teste Tukey $(\mathrm{P}<0,05)$.

Valores entre parênteses indicam amplitude de variação.

O VCM aumentou de forma significativa com a idade dos animais, oscilando entre 59,38 e $66,97 \mathrm{fl}$. Não houve aumento até 72 meses de idade $(\mathrm{P}>0,05)$, mas, ele ocorreu a partir de 72 meses $(\mathrm{P}<0,05)$ em relação às faixas etárias anteriores. A variação observada nos valores do VCM é relatada por vários pesquisadores (Theilen et al., 1967; Mammerickx et al., 1978; Marçal, 1989), enquanto outros não mencionaram diminuição do VCM ou não verificaram variações significativas dos índices hematimétricos absolutos (Penny et al., 1966; Wingfield e Tumbleson, 1973).

Em relação ao $\mathrm{HCM}$, os resultados mostram oscilações entre 18,01 e 20,63pg. Houve aumento significativo $(\mathrm{P}<0,05)$ da segunda para a terceira e quarta faixas etárias. A influência dos fatores etários foi relatada por outros autores (Penny et al., 1966; Theilen et al., 1967; Mammerickx et al., 1978; Marçal, 1989; Távora, 1997).
Não houve variação na $\mathrm{CHCM} \quad(\mathrm{P}>0,05)$ atribuída à idade. A oscilação foi somente de 30,90 a $31,83 \mathrm{~g} / \mathrm{dl}$. Vários autores também não verificaram influência da idade sobre a CHCM (Wingfield e Tubleson, 1973; Mammerickx et al., 1978; Távora, 1997). Os resultados da CHCM diferem dos observados por Marçal (1989), Ayres (1994) e Birgel Junior (2001).

\section{CONCLUSÕES}

Os valores de referência obtidos para o eritrograma de fêmeas bovinas da raça Aquitânica, com idade acima de 12 meses, criadas na região Norte do Paraná, mostram-se dentro da faixa de normalidade citada na literatura internacional, e próximos aos valores relatados para outras raças bovinas criadas no Brasil. 


\section{REFERÊNCIAS BIBLIOGRÁFICAS}

ALENCAR FILHO, R.A. Leucograma de bovinos nacionais e estrangeiros com vistas ao estudo da leucose. Biológico, v.37, p.181-184, 1970.

AYRES, M.C.C. Avaliação da influência de fatores relacionados ao sexo sobre a variabilidade do eritrograma de zebuínos (Bos indicus, Linnaeus, 1758) da raça Nelore, criados no Estado de São Paulo. Vet. Bras. Saúde Prod. Anim., v.1, p.31-36, 2001.

AYRES, M.C.C. Eritrograma de zebuinos (Bos Indicus), Linnaeus, 1758) da raça Nelore, criados no Estado de São Paulo: Influência de fatores etários, sexuais e do tipo racial. 1994. 141f. Dissertação (Mestrado) - Faculdade de Medicina Veterinária e Zootecnia, Universidade de São Paulo, São Paulo.

BIRGEL Jr., E.H.; D'ANGELINO, J.L.; BENESSI, F.J. et. al. Valores de referência do leucograma de bovinos da raça Jersey criados no Estado de São Paulo. Braz. J. Vet. Res. Anim. Sci., v.38, p.1-11, 2001.

COSTA, J.N. Leucograma de zebuinos (Bos indicus, Linnaeus, 1758) sadios da raça Nelore criados no Estado de São Paulo. Influência dos fatores etários e sexuais. 1994. 75f. Dissertação (Mestrado) Faculdade de Medicina Veterinária e Zootecnia, Universidade de São Paulo, São Paulo.

DIRKSEN, G. Exame clínico dos bovinos. 3.ed. Rio de Janeiro: Guanabara Koogan, 1993. 228p.

FAGLIARI, J.J., SANTANA, A.E.; LUCAS, F.A. et al. Constituintes sangüíneos de bovinos lactentes, desmamados e adultos das raças Nelore (Bos indicus) e Holandesa (Bos taurus) e de bubalinas (Bubalus bubalis) da raça Murrah. Arq. Bras. Med. Vet. Zootec., v.50, p.273-282, 1998.

GONÇALVES, R.C.; PAES, P.R.O.; ALMEIDA, C.T. et al. Influência da idade e sexo sobre o hemograma, proteínas séricas totais, albumina e globulina de bovinos sadios da raça Guzerá (Bos indicus). Vet. Not., v.7, p.61-68, 2001.

IAPAR. Cartas climáticas do Estado do Paraná. Londrina, 2001.

JAIN, N.C. Essencial of veterinary hematology. Philadelphia: Lea \& Febiger, 1978. cap.7, p.133-158: Erytrocyte Physiology and changes in disease.

KRACHE, R. Doenças do sangue. 2.ed. Rio de Janeiro: Guanabara Koogan, 1943. 417p.

LORENZ, R.J.; STRAUB, O.C.; DONELLY, W.J. et al. Bovine Hematology. II. Comparative breed studies on the leucocytes parameters of several European cattle breeds as determined in national laboratories. Zent. Vet., Reihe B, v.25 p.245-56, 1978.

LUMSDEN, J.H.; MULLEN, K.; ROWE, R. Hematology and biochemistry reference values for female Holstein cattle. Can. J. Comp. Med., v.44, p.24-31, 1980.

MAMMERICKX, M.; LORENZ, R.J.; STRAUB, O.C. et al. Bovine hematology. IV Compartive breed studies on the eritrocyte parameters of 16 European cattle breeds as determined in the common reference laboratory. Zent. Vet., Reihe B, v.25, p.484-98, 1978.

MARÇAL, W.S. Eritrograma de bovinos (Bos taurus, Linnaeus, 1758), fêmeas da raça Holandesa preta e branca, sadias, criadas no Estado de São Paulo, 1989. 128f. Dissertação (Mestrado) - Faculdade de Medicina Veterinária e Zootecnia Universidade de São Paulo, São Paulo.

MARÇAL, W.S.; BIRGEL, E.H.; D'ANGELINO, J.L. et al. Estudo clínico do eritrograma de bovinos leiteiros em função da idade. Semina, v.16, p.145-142, 1995.

PENNY, R.H.C.; SCOFIELD, A.M.; CEMBROWICZ, H. Haematological values for the clinically normal bull. Br. Vet. J., v.122, p.239-247, 1966.

SCHALM, O.W.; JAIN, N.C.; CARROL, E.J. Veterinary hematology. 3.ed. Philadelphia: Lea \& Febiger, 1975. p.122-143.

SISTEMA de análises estatísticas e genéticas - SAEG. Viçosa: UFV, 1983. 159p.

TÁVORA, J.P.F. Hemograma de bovinos das raças Gir, Girolando e Holandesa criados no Estado de São Paulo. Estabelecimento dos valores de referência e avaliação das influências de fatores de variabilidade raciais, etárias e sexuais. 1997. 163f. Tese (Doutorado) - Faculdade de Medicina Veterinária e Zootecnia, Universidade de São Paulo, São Paulo.

THEILEN, G.H.; BLAMPIED, N.Q.; HARROLD, B. et al. Hematologic survey of cattle on the Island of Jersey Witth reference to the reported incidence of limphosarcaom (Leukemia). Am. J. Vet. Res., v.28, p.1313-318, 1967.

TURRA, A. Raça Aquitânica. Disponível em: http:www.revistadaterra.com.br/aquitanica.php. Acessado em: 10 mar. 2004, 16:25:30.

WINFIELD, W.E.; TUMBLESON, M.E. Hematologic parameters, as a function of age, in female dairy cattle. Cornell Vet., v.63, p.72-80, 1973. 